\title{
Crop Diversification in Jammu and Kashmir: Pace, Pattern and Determinants
}

\author{
Naseer Hussain Bazaz ${ }^{1}$, Dr. Imtiyaz ul Haq ${ }^{2}$ \\ ${ }^{I}$ (Ph. D Scholar, P.G Department of Economics, University of Kashmir, India) \\ ${ }^{2}$ (Assistant Professor, P.G Department of Economics, University of Kashmir, India)
}

\begin{abstract}
In this paper an attempt has been made to understand the patterns and determinants of crop diversification in Jammu and Kashmir agriculture. Entropy index has been applied to explore the extent of diversification or specialization across crops and districts. Entropy indices of diversification and Gross Cropped Area (GCA) under non-foodgrains were regressed on different explanatory variables. The study revealed that the crop sector of Jатти and Kashmir agriculture at an aggregate level is gradually diversifying in favour of high-value crops. However, while analyzing the extent of diversification at regional level, the Jammu division is witnessing a specialization in foodgrain crops, whileas Kashmir division depicting a trend towards diversification.Further, an analysis of determinants that facilitated the process of crop diversification revealed all the factors considered under study have significantly affected crop diversification in the state, except fertilizer consumption.
\end{abstract}

Keywords - Foodgrains, Diversification, Specialization, Entropy Index, Jammu and Kashmir

\section{Introduction}

In the state of Jammu and Kashmir, agriculture is the key sector for employment and income generation, because large scale industrialization is not ecologically desirable, and the infrastructure is too poor to attract industries. Therefore, agricultural sector continues to remain the important sector for socio-economic development of the people. With serious constrains on area expansion and declining scope of other sources of growth of agriculture output, the diversification of agriculture towards non-foodgrains and high value cash crops including fruits and vegetables, compatible with the comparative advantage of the region is suggested as a viable solution. These crops have potential of income augmentation, employment generation, poverty alleviation and export promotion [1]. According to a study, in the state of Jammu and Kashmir, the scope to raise output through diversification is highest in the country as one per cent shift in area from foodgrains to non-foodgrains entails more than 3 per cent growth rate in crop output [2].

There is a growing concern about the viability of small farm agriculture in the state as the small landholders have dominated the J\&K agriculture in the past, and the trend is likely to continue as well. The average size of landholdings witnessed a declining trend, and in 2005-06 it was as low as 0.67 hectare, which is below the national average. It is contended that viability of small farms can be improved through diversification of agriculture into higher value crops, mainly fruits and vegetables [3]. Against this background, a modest attempt has been made to understand the patterns and determinants of agricultural diversification and the constraints it faces so that it would help to frame appropriate agricultural strategy to boost the agricultural economy of the state. Therefore, the study intends to (i) study the temporal changes in the process of agricultural diversification in terms of proportionate area share (ii) examine the pace and extent of agriculture diversification in the state, and (iii) identify determinants of agricultural diversification. In consonance with these objectives the paper in section-2 starts with the discussion on the methodology used and the sources of the data employed. Section-3 provides a detailed analysis of changes in cropping pattern covering a period of three decades from1981-82 to 2010-11. In section-4, Entropy index has been employed to gauge the pace and pattern of crop diversification at the district and state levels. An attempt has been made, in section-5, to examine with the help of multiple regression model, the major determinants responsible for the changing cropping pattern within the state of Jammu and Kashmir. Finally, on the basis of analysis of the data and the results obtained therein, the paper brings out some important conclusions having policy implications.

\section{Data and Methods}

The study is based on secondary data. The data has been collected from various secondary sources such as Ministry of Agriculture, Government of India, New Delhi; Directorate of Economics and Statistics, Government of Jammu \& Kashmir; and Office of the Financial Commissioner, Government of Jammu and Kashmir.In order to explore the extent of diversification or specialization in major crop groups, there are number of methods and important ones include (i) Index of maximum proportion (ii) Herfindal index (iii) 
Simpson Index (iv) Ogive Index, and (v) Entropy Index. In our study, Entropy Index (EI) has been applied by using the following Entropy Index equation:

$\mathrm{EI}=\sum_{\mathrm{i}=1}^{\mathrm{N}} \mathrm{Pi}\left[\log \left(1 / \mathrm{P}_{\mathrm{i}}\right)\right](1)$

Where, $\mathrm{P}_{\mathrm{i}}$ is the area share or proportion of crop $\mathrm{i}$ and $\mathrm{N}$ is the number of crops that are analyzed. EI is weighted sum of proportions where the weight is $\log \left(1 / \mathrm{P}_{\mathrm{i}}\right)$. It varies inversely with the proportions. The index varies between 0 and $\log (\mathrm{N})$, where value 0 implies a state of complete specialization and $\log (\mathrm{N})$ indicates condition of perfect diversification. The regression analysis was applied to the secondary source cross section data pertaining to different districts for the year 2005-06. The values obtained by using Entropy indexpertaining to food and non-foodgrain crops were regressed on different explanatory variables to identify the determinants of crop diversification. Alternatively, Gross Cropped Area (GCA) under non-foodgrains was regressed on the same explanatory variables to supplement the analysis. The following equation was used:

$Y=a+b_{1} X_{1}+b_{2} X_{2}+b_{3} X_{3}+b_{4} X_{4}+b_{5} X_{5}+u(2)$

Where dependent variable $\mathrm{Y}=\mathrm{EI}$ or GCA under non-foodgrains.

$\mathrm{X}_{1}$ i irrigated area per thousand hectare of the gross cropped area,

$\mathrm{X}_{2}=$ road length per thousand hectare of the gross cropped area,

$\mathrm{X}_{3}=$ average farm size,

$\mathrm{X}_{4}=$ fertilizer consumption in terms of nutrients per thousand hectares of net sown area,

$\mathrm{X}_{5}=$ annual rainfall in millimeters,

$\mathrm{U}=$ error term assumed to follow normal distribution with zero mean and constant variance.

\section{Changes in Cropping Pattern}

Table 2 presents five years average of relative area (as percentage to gross cropped area) under crops and crop groups in Jammu and Kashmir from 1981-82 to 2010-11. Significant changes are observed in the nature and direction of cropping pattern. For rice, a substantial decrease in relative area share from 26.77 per cent in 1981-85 to 22.75 per cent in 2006-10 is observed. However, during the same period, a marginal increase is witnessed for maize where the acreage increased from 27.45 per cent to 27.63 per cent. Compared to maize, substantial increase is witnessed in the share of wheat acreage from 21.24 per cent in 1981-85 to 24.65 per cent in 2006-10. However, cereals as a group, showed continuous decline as its share got reduced from 80.14 per cent to 78.59 per cent during the same period. The decline is attributed to an absolute fall in area under rice, bajra, ragi and other cereals. As far as pulses are concerned the situation is worrisome as the absolute as well as proportionate area share under this group declined drastically. The relative area share decreased to just 2.62 per cent in 2006-10 which is nearly half of what it used to be in early eighties.

On the other hand, oilseeds particularly rapeseed/mustard demonstrated spectacular performance. The increase in area under oilseeds was due to the fact that at the national level the government initiated a series of measures during 1980s. The two most important components were price initiative and technological developments. Prices of oilseeds were raised substantially not in isolation but in relation to those of other crops, especially cereals such as wheat and rice [4]. On the technological front, the progress was rather slow. The series of measures to boost production of oilseeds commenced initially with the introduction of National Oilseeds Development Project (NODP) in 1984-85.

Along with the area gains in oilseeds, area under other commercial crops viz. plantation crops, spicescondiments, fruits-vegetables witnessed a remarkable increase in both absolute as well as in relative terms. The relative area share in condiments-fruits-vegetables, as a group increased from 5.60 per cent in 1981-85 to about 7.91 per cent in 2006-10. However, during the same period the relative share of fibers witnessed a gradual decline from 0.13 per cent to just 0.02 per cent. Whileas, plantation and fodder crops, as a group performed well, as its relative area share increased from 3.34 per cent in 1981-85 to 5.14 per cent in 2006-10.

Table 1: Changes in Cropping Pattern of Food and Non-Food Crops inJammu and Kashmir

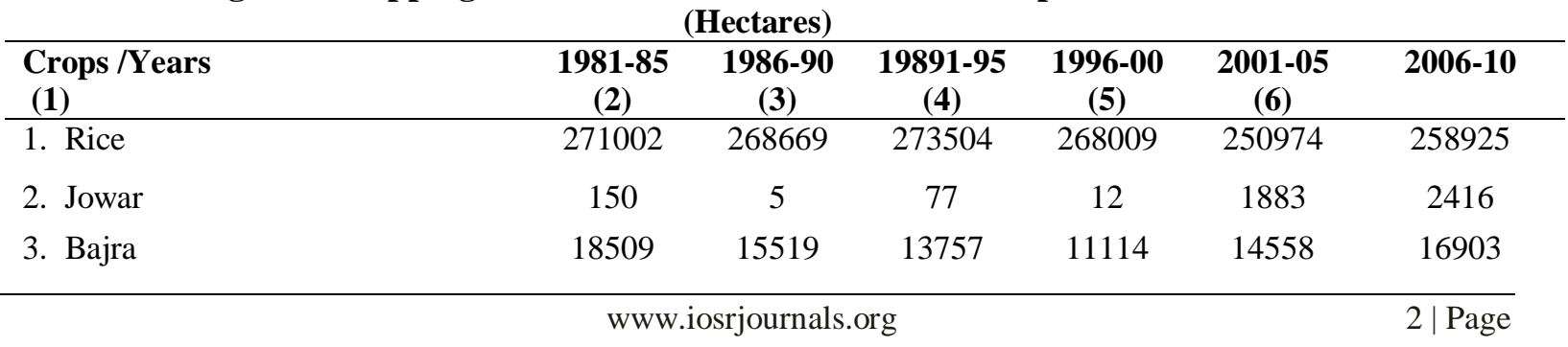


Crop Diversification in Jammu and Kashmir: Pace, Pattern and Determinants

4. Maize
5. Ragi
6. Wheat
7. Barley
8. Other Cereals

Total Cereals (1-7)

8. Gram

9. Tur/Arhar

10.Other Pulses

11.Total Pulses (8-11)

Total Foodgrains (1-11)

12. Sugarcane

13. Condiments

14. Fruits-Vegetables

15. Other Food Crops

Sugarcane Condiments-

Fruits-Vegetables(12-

15)

16. Groundnut
17. Sesame
18. Rapseed/Musterd
19. Linseed
20. Other Oilseeeds

Total Oilseeds (16-20)

21. Cotton

22. Sannhemp

23. Other Fibres

Total Fibres (21-23)

24. Dyes\& Tanning

25. Tobacco

26. Indian hemp

28. Fodder Crops

29. Others Non-food Crops

Drugs-Plantation-Fodder Other Non-Food Crops

All Major Crops/GCA

$\begin{array}{cccccc}279210 & 292741 & 297011 & 311132 & 324150 & 312427 \\ 8806 & 7398 & 9002 & 8635 & 8154 & 5863 \\ 215003 & 237446 & 246651 & 244986 & 253632 & 280557 \\ 9656 & 8359 & 7631 & 8743 & 10925 & 13091 \\ 9035 & 7932 & 5773 & 5204 & 4638 & 4353 \\ \mathbf{8 1 1 3 7 1} & \mathbf{8 3 8 0 6 9} & \mathbf{8 5 3 4 0 6} & \mathbf{8 5 7 8 3 5} & \mathbf{8 6 8 9 1 4} & \mathbf{8 9 4 5 3 5} \\ 944 & 1021 & 402 & 396 & 237 & 225 \\ 3 & 23 & 34 & 37 & 4 & 12 \\ 46432 & 40891 & 34184 & 30825 & 28446 & 29582 \\ 47379 & 41935 & 34620 & 31258 & 28687 & 29819 \\ \mathbf{8 5 8 7 5 0} & \mathbf{8 8 0 0 0 4} & \mathbf{8 8 8 0 2 6} & \mathbf{8 8 9 0 9 3} & \mathbf{8 9 7 6 0 1} & \mathbf{9 2 4 3 5 4} \\ 718 & 493 & 318 & 177 & 160 & 53 \\ 1629 & 1896 & 2132 & 2339 & 2508 & 2640 \\ 53620 & 57228 & 63638 & 65059 & 75685 & 87226 \\ 706 & 136 & 334 & 353 & 841 & 202 \\ \mathbf{5 6 6 7 3} & \mathbf{5 9 7 5 3} & \mathbf{6 6 4 2 2} & \mathbf{6 7 9 2 8} & \mathbf{7 9 1 9 4} & \mathbf{9 0 1 2 1}\end{array}$

$\begin{array}{cccccc}499 & 449 & 448 & 153 & 20 & 10 \\ 6771 & 9535 & 8840 & 6007 & 5677 & 5299 \\ 51585 & 53450 & 59539 & 64473 & 61008 & 58937 \\ 2538 & 1604 & 1223 & 882 & 257 & 159 \\ 121 & 241 & 390 & 231 & 39 & 119 \\ \mathbf{6 1 5 1 4} & \mathbf{6 5 2 7 9} & \mathbf{7 0 4 4 0} & \mathbf{7 1 7 4 6} & \mathbf{6 7 0 0 1} & \mathbf{6 4 5 2 4} \\ 464 & 174 & 118 & 102 & 43 & 37 \\ 780 & 601 & 453 & 291 & 194 & 225 \\ 176 & 113 & 57 & 46 & 13 & 32 \\ \mathbf{1 4 2 0} & \mathbf{8 8 8} & \mathbf{6 2 8} & \mathbf{4 3 9} & \mathbf{2 5 0} & \mathbf{2 9 4} \\ 3425 & 3823 & 4364 & 4817 & 2879 & 2687 \\ 112 & 58 & 65 & 44 & 14 & 9 \\ 430 & 38 & 2 & 6 & 36 & 83 \\ 28959 & 36998 & 42129 & 45075 & 50754 & 55168 \\ 936 & 728 & 697 & 688 & 518 & 630 \\ \mathbf{3 3 8 6 2} & \mathbf{4 1 6 4 5} & \mathbf{4 7 2 5 7} & \mathbf{5 0 6 3 0} & \mathbf{5 4 2 0 1} & \mathbf{5 8 5 7 7}\end{array}$

$\begin{array}{llllll}1012219 & 1047569 & 1072773 & 1079836 & 1098247 & 1137870\end{array}$

Source: Computed by authors on the basis of data obtained from office of the Financial Commissioner Revenue, Government of Jammu and Kashmir.

Table 2: Composition of Food and Non-Food Crops in Jammu and Kashmir (Percent of Gross Cropped Area)

\begin{tabular}{lcccccc}
\hline $\begin{array}{l}\text { Crops /Years } \\
\text { (1) }\end{array}$ & $\mathbf{1 9 8 1 - 8 5}$ & $\mathbf{1 9 8 6 - 9 0}$ & $\mathbf{1 9 8 9 1 - 9 5}$ & $\mathbf{1 9 9 6 - 0 0}$ & $\mathbf{2 0 0 1 - 0 5}$ & $\mathbf{2 0 0 6 - 1 0}$ \\
\hline 1. Rice & $\mathbf{( 2 )}$ & $\mathbf{( 3 )}$ & $\mathbf{( 4 )}$ & $\mathbf{( 5 )}$ & $\mathbf{( 6 )}$ & 22.85 \\
2. Jowar & 26.77 & 25.64 & 25.49 & 24.81 & 22.75 \\
3. Bajra & 0.015 & 0.0005 & 0.007 & 0.001 & 0.171 & 0.212 \\
4. Maize & 1.82 & 1.481 & 1.282 & 1.029 & 1.325 & 1.485 \\
5. Ragi & 27.45 & 27.944 & 27.68 & 28.81 & 29.51 & 27.63 \\
6. Wheat & 0.87 & 0.706 & 0.839 & 0.799 & 0.742 & 0.515 \\
7. Barley & 21.24 & 22.66 & 22.99 & 22.68 & 23.09 & 24.65 \\
8. Other Cereals & 0.95 & 0.797 & 0.711 & 0.809 & 0.994 & 1.150 \\
Total Cereals (1-7) & 0.89 & 0.757 & 0.538 & 0.482 & 0.422 & 0.382 \\
& $\mathbf{8 0 . 1 4}$ & $\mathbf{7 9 . 9 9}$ & $\mathbf{7 9 . 5 3}$ & $\mathbf{7 9 . 4 1}$ & $\mathbf{7 9 . 1 0}$ & $\mathbf{7 8 . 5 9}$ \\
\hline
\end{tabular}



8. Gram
9. Tur/Arhar
10. Other Pulses
11.Total Pulses (8-11)

Total Foodgrains (1-11)

12. Sugarcane

13. Condiments

14. Fruits-Vegetables

15. Other Food Crops

Sugarcane CondimentsFruits-Vegetables(12-

15)
16. Groundnut
17. Sesame
18. Rapseed/Musterd
19. Linseed
20. Other Oilseeeds

Total Oilseeds (16-20)

21. Cotton

22. Sannhemp

23. Other Fibres

Total Fibres (21-23)

24. Dyes\& Tanning

25. Tobacco

26. Indian hemp

28. Fodder Crops

29. Others Non-food Crops

Drugs-Plantation-Fodder Other Non-Food Crops

All Major Crops/GCA

$\begin{array}{cccccc}0.093 & 0.097 & 0.037 & 0.036 & 0.022 & 0.019 \\ 0.0003 & 0.0002 & 0.0003 & 0.0003 & 0.0004 & 0.001 \\ 4.58 & 3.90 & 3.186 & 2.854 & 2.590 & 2.599 \\ 4.68 & 4.00 & 3.22 & 2.89 & 2.61 & 2.62 \\ \mathbf{8 4 . 8 2} & \mathbf{8 3 . 9 9} & \mathbf{8 2 . 7 5} & \mathbf{8 2 . 3 0} & \mathbf{8 1 . 7 3} & \mathbf{8 1 . 2 0} \\ 0.070 & 0.047 & 0.029 & 0.016 & 0.014 & 0.005 \\ 0.161 & 0.181 & 0.198 & 0.216 & 0.228 & 0.232 \\ 5.30 & 5.462 & 5.932 & 6.024 & 6.891 & 7.665 \\ 0.070 & 0.013 & 0.031 & 0.032 & 0.076 & 0.017 \\ \mathbf{5 . 6 0} & \mathbf{5 . 7 0} & \mathbf{6 . 1 9} & \mathbf{6 . 2 8} & \mathbf{7 . 2 1} & \mathbf{7 . 9 1}\end{array}$

$\begin{array}{lccccc}0.049 & 0.042 & 0.042 & 0.014 & 0.002 & 0.0009 \\ 0.669 & 0.910 & 0.824 & 0.556 & 0.517 & 0.465 \\ 5.096 & 5.10 & 5.55 & 5.971 & 5.55 & 5.17 \\ 0.250 & 0.153 & 0.114 & 0.081 & 0.023 & 0.014 \\ 0.012 & 0.023 & 0.036 & 0.021 & 0.003 & 0.010 \\ \mathbf{6 . 0 7} & \mathbf{6 . 2 2} & \mathbf{6 . 5 6} & \mathbf{6 . 6 4} & \mathbf{6 . 1 0} & \mathbf{5 . 6 6} \\ 0.045 & 0.016 & 0.011 & 0.009 & 0.004 & 0.003 \\ 0.077 & 0.057 & 0.042 & 0.026 & 0.017 & 0.019 \\ 0.017 & 0.010 & 0.005 & 0.004 & 0.001 & 0.003 \\ \mathbf{0 . 1 3 9} & \mathbf{0 . 0 8 3} & \mathbf{0 . 0 5 8} & \mathbf{0 . 0 3 9} & \mathbf{0 . 0 2 2} & \mathbf{0 . 0 2 4} \\ 0.338 & 0.365 & 0.406 & 0.446 & 0.262 & 0.236 \\ 0.011 & 0.005 & 0.006 & 0.004 & 0.001 & 0.0008 \\ 0.043 & 0.004 & 0.0002 & 0.0006 & 0.003 & 0.007 \\ 2.860 & 3.531 & 3.927 & 4.174 & 4.621 & 4.848 \\ 0.082 & 0.049 & 0.064 & 0.063 & 0.047 & 0.052 \\ \mathbf{3 . 3 4 4} & \mathbf{3 . 9 7 4} & \mathbf{4 . 4 0 4} & \mathbf{4 . 6 8 8} & \mathbf{4 . 9 3 5} & \mathbf{5 . 1 4 7} \\ & & & & & -100 \\ \mathbf{1 0 0} & \mathbf{1 0 0} & \mathbf{1 0 0} & \mathbf{1 0 0} & \mathbf{1 0 0} & \mathbf{1 0 0}\end{array}$

Source: Computed by authors on the basis of data obtained from office of the Financial Commissioner Revenue, Government of Jammu and Kashmir.

From the above analysis it appears that the major beneficiaries as a group in terms of increased area under cultivation were oilseeds, condiments-fruits-vegetables, and plantation crops. This development indicates a movement of shifting area in favour of non-foodgrains from foodgrains, and therefore, indicating an increasing tendency towards crop diversification among major crop groups. However, from the above analysis it is also evident that among the crop groups there are certain crops whose share is increasing at the cost of others. Therefore, it becomes pertinent to measure the extent to which the crop diversification or specialization has taken place in the state.

\section{Pace and Pattern of Crop Diversification}

Diversification is an integral part of the process of structural transformation of an economy and the economy of Jammu and Kashmir is no exception. As its economy is also diversifying at the macro level with the secondary and tertiary sectors becoming progressively more important in terms of their contributions to Gross State Domestic Product (GSDP). Diversification within agriculture is of two types: (i) crop diversification and (ii) enterprise diversification involving inter-crop and inter-enterprise shifts of resources respectively [5]. The extent and pattern of crop diversification among major crop groups in the state from 1981-82 to 2010-11, under five year averages, is evident from the values of Entropy index as depicted in the table given below. 
Table 3: Entropy Index Values of major Crops Groups in Jammu and Kashmir

$\begin{array}{lcccccc}\text { Crops/Years } & 1981-85 & 1986-90 & 1991-95 & 1996-00 & 2001-05 & 2006-10 \\ \text { 1. Cereals } & 1.3245 & 1.2951 & 1.2821 & 1.2696 & 1.2944 & 1.3015 \\ \text { 2. Pulses } & 0.0996 & 0.1186 & 0.0683 & 0.0741 & 0.0492 & 0.0467 \\ \text { 3. Sugarcane-Fruits-Vegetables } & 0.2636 & 0.2038 & 0.2025 & 0.1979 & 0.2125 & 0.1518 \\ \text { 4. Oilseeds } & 0.5724 & 0.5895 & 0.5333 & 0.3881 & 0.3225 & 0.3154 \\ \text { 5. Fibres } & 0.9493 & 0.8303 & 0.7603 & 0.8422 & 0.6496 & 0.7048 \\ \text { 6.Plantation-Fodder Crops } & 0.5484 & 0.4199 & 0.3926 & 0.3916 & 0.2674 & 0.2600 \\ \text { 7. All Major Crop Groups (1-6) } & 0.7749 & 0.7774 & 0.7855 & 0.7859 & 0.7911 & 0.8026 \\ \text { 8. Foodgrains (1-2) } & 0.2134 & 0.1914 & 0.1644 & 0.1520 & 0.1414 & 0.1424 \\ \text { 9. Non-Foodgrains (3-6) } & 1.1108 & 1.1082 & 1.1031 & 1.1008 & 1.0947 & 1.0888\end{array}$

Source: Computed by authors on the basis of data obtained from office of the Financial Commissioner, Govt. of J\&K.

The results that are summarized in (Table 3) make it markedly clear that at the state level the overall index for all major crop groups have risen from 0.774 in 1981-85 to 0.802 in 2006-10, thereby indicating an increase in crop diversification at the aggregate level. This is due to the fact that area under fruits-vegetables and fodder crops have shown a substantial increase, more particularly in Kashmir division, during the reference period. This trend is in conformity with the finding that, 'as the cultivation of horticultural crops being laborintensive, suits the small holders well who make use of their family labor force and ensure regular flow of income'[6]. But it is pertinent to recognize that all types of shifts of resources across crops or enterprises do not lead to higher degree of diversification. This is particularly true when the resources get concentrated increasingly over time in only one or two more profitable and/or less risky crops or enterprises [5]. Consistent with the fact, the situation for an individual crop group is quite different than at the aggregate level. That is, in most of the individual crop groups the values of index have shown a declining trendandhencedepicting a trend towards specialization. This is due to the fact that within the crop group like cereals, area under wheat and maize have shown a marginal increase whereas at the same time area under rice, bajra, ragi and other cereals have witnessed a decline. The area under maize has increased because of the increased demand for fodder to feed the poultry, and wheat seems to have benefited from the favorable price policy over a period of years now. Specialization in pulses is not on account of increased area in any crop among the crop group, but is due to the fact that the proportionate share of all crops in this group has declined, while the area share in some crops have declined much faster than others, thereby implying a specialization over the years. With respect to the nonfoodgrain crops, the favorable movement of area towards these crops was again at the cost of mainly coarse cereals and some irrigated area under rice.

Table 4: District wiseTrends towards Diversification/Specialization in Jammu and Kashmir Districts T.E 1982-83 T.E 1992-93 T.E 2002-03 T.E 200910

Increasing Spread

$\begin{array}{lll}\text { 1. Srinagar } & 1.00713 \\ \text { 2. Budgam } & 0.84897 \\ \text { 3. Anantnag } & 0.90695 \\ \text { 4. Pulwama } & 1.19820 \\ \text { 5. Baramulla } & 0.84163 \\ \text { 6.Leh } & 0.71687\end{array}$

$\begin{array}{lll}1.09152 & 1.18060 & 1.16379 \\ 1.00940 & 0.93885 & 1.03305 \\ 1.00932 & 1.07129 & 1.22676 \\ 1.25119 & 1.30978 & 1.36162 \\ 0.89497 & 1.03566 & 0.98466 \\ 0.77390 & 0.77353 & 0.81985 \\ \text { Static Spread/Concentration } & \end{array}$

7. Poonch

8. Doda

$\begin{array}{lll}0.299766 & 0.309413 & 0.306685 \\ 0.405405 & 0.414262 & 0.414166\end{array}$

Increasing concentration

9. Jammu
10. Udhamphur
11. Rajouri
12. Kathua
13. Kargil
14. Kupwara

0.632599
0.415910
0.346614
0.685905
1.010530
0.596782

$\begin{array}{ll}0.581123 & 0.329699 \\ 0.386739 & 0.292225 \\ 0.332798 & 0.205464 \\ 0.690834 & 0.595527 \\ 1.04560 & 0.949888 \\ 0.529018 & 0.616707\end{array}$

0.289486

0.426817

0.454264
0.295010
0.171959
0.488079
0.955565
0.392726
T.E 1982-83 T.E 2009-10

Percentage of Non-Foodgrain

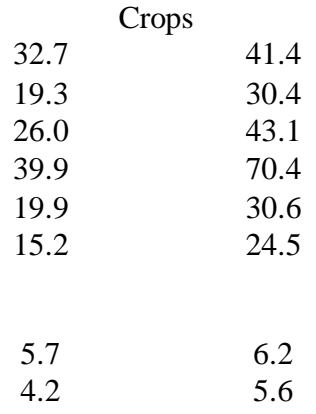

$13.6 \quad 10.3$


Source: Computed by authors on the basis of data obtained from office of the Financial Commissioner, Govt. of Jammu and Kashmir.

The districtwise values of Entropy index suggest a pronounced diversification taking place in the various districts of Kashmir division. This is in contrast to the specialization trend in all the districts of Jammu division, except Poonch and Doda districts. Crop diversification is more pronounced in areas having higher concentration of small holders like Srinagar, Budgam, Anantnag, Pulwama, Baramulla and Leh where the average farm size is less than the state average. In Kashmir division, the changing scenario of agriculture, particularly decline in foodgrain productivity, small average farm size and comparative advantage in fruitsvegetables in the region has forced the farming community to move towards crop diversification in favour of non-foodgrain crops. The districts showing a significant decline in diversification indices or increaseinconcentrationareJammu,Udhamphur,Rajouri,Kathua, Kargil andKupwara. However, the diversification indices for two districts of Jammu division namely Poonch and Doda has Shown static or divergent trend during the reference period. The per cent of GCA undernon-foodgrain crops, another measurement of diversification, has increased significantly in all districts of Kashmir division except Kargil and Kupwara. Whileas, decrease in GCA under non-foodgrain crop is observed in all districts of Jammu divisions with the exception of Poonch and Doda.

\section{Determinants of Crop Diversification}

This section discusses the result of a regression analysis undertaken to assess the determinants of agricultural diversification. The log-linear regression analysis was done using cross section data from secondary sources regarding various districts for the year 2005-06. In order to assess the determinants of diversification, measures of agricultural diversification like Entropy Index and GCA under non-foodgrains were calculated and these were regressed on different explanatory variables. The estimated results with respect to the Entropy Index and also the percent of GCA under non-foodgrain crops are presented below in Table 5. With the increase in area under irrigation one would expect diversification to increase. It can be seen that diversification based on Entropy Index and GCA under non-foodgrains was affected positively and significantly by irrigation. Average farm size is always considered as important determinant of crop diversification because of its policy implications. The variable was highly significant with negative sign, indicating that small farms are relatively more diversified than larger farms.

Table 5-Regression Coefficients Estimates

\begin{tabular}{lccccccc}
\hline $\begin{array}{l}\text { Variable } \\
\text { Details }\end{array}$ & $\begin{array}{c}\text { Area } \\
\text { Irrigated } \\
\text { (per } \\
\text { thousand ha } \\
\text { of GCA) } \mathrm{X}_{2}\end{array}$ & $\begin{array}{c}\text { Road } \\
\text { length(per } \\
\text { thousand ha } \\
\text { of GCA) } X_{1}\end{array}$ & $\begin{array}{c}\text { Farm Size } \\
\text { (average } \\
\text { holding size } \\
\text { in } \\
\text { hectares) }\end{array}$ & $\begin{array}{c}\text { Fertilizer } \\
\text { Consumption( } \\
\text { per thousand } \\
\text { crop hectares) } \\
\mathrm{X}_{4}\end{array}$ & $\begin{array}{c}\text { Rainfall (in } \\
\text { millimeters) } \\
\mathrm{X}_{5}\end{array}$ & $\mathrm{R}^{2}$ & $\begin{array}{c}\text { Adjusted } \\
\mathrm{R}^{2}\end{array}$ \\
\hline $\begin{array}{l}\text { Entropy } \\
\text { Index }\end{array}$ & 0.610 & -0.150 & -0.478 & 0.077 & 0.317 & $91.2 \%$ & $85.7 \%$ \\
GCA & $(4.36)$ & $(-1.00)$ & $(-3.00)$ & $(0.55)$ & $(2.51)$ & & \\
$\begin{array}{l}\text { under } \\
\text { Non-Food }\end{array}$ & 0.701 & -0.373 & -0.51 & 0.111 & 0.347 & $94.6 \%$ & $91.2 \%$ \\
Crops & $(6.37)$ & $(-3.05)$ & $(-4.08)$ & $(1.00)$ & $(3.49)$ & & \\
\hline
\end{tabular}

Note: Figures in parentheses indicate ' $\mathrm{t}$ ' values.

Rainfall was taken as proxy variable for climate in the study to assess the effect of climate on crop diversification; the results were positive and significant. Expansion of road length is considered to strengthen the market related structure and thereby encourage farmers to come out of their subsistence farming. Moreover, diversification if perceived in terms of increase in area under non-foodgrain crops, increase in road length can become a positive determinant of diversification. This is due to the fact that non-foodgrain crops also include area under fruits and vegetables, many of these are perishable in nature, and hence positive relationship is expected between road and percent of GCA under non-foodgrain crops. However, in our study, the estimates are negative and significant, in terms of GCA under non-foodgrain crops. This finding is also supplemented by Entropy value regressed on road length variable which, however, shows a negative but insignificant relation.

\section{Concluding Remarks}

The foregoing analysis reveals intercrop area shift in favour of some high yielding crops like wheat and maize. However, the changes in cropping pattern were more pronounced in favour of non-foodgrain crops viz. fruits-vegetables, plantation, fodder, condiments and spices. As a result of such shifts in cropping pattern, the crop sector of $J \& K$ agriculture at the state level is gradually diversifying in favour of high-value crops. But, 
in most of the individual crop groups the values of index have shown a declining trend. This is due to the fact, that among the crop groups there are certain crops whose share is increasing at the cost of others and hence encouraging a trend towards specialization. However, while analyzing the extent of diversification at regional level, the Jammu division is witnessing a specialization in foodgrain crops, whileas Kashmir division depicting a trend towards diversification. Therefore, the trend towards diversification, which we are witnessing at the state level, is due to the fact that it is more pronounced in Kashmir division. One of the reasons of this trend in Kashmir division is on account of small farm size which is less than state average, whileas, in Jammu division it is more than state average. Therefore, given the different agro-climatic conditions and coupled with different land holding sizes, both divisions of the state require a different policy treatment. Further, an analysis of determinants that facilitated the process of crop diversification revealed all the factors considered under study have significantly affected crop diversification except fertilizer consumption. The results of the present study throw some light on policy instruments which can be used to augment the process of agricultural diversification in the state of Jammu and Kashmir. While supporting the diversification of crop sector, particularly in Kashmir division, one cannot overlook the aspect of self-sufficiency in terms of foodgrain crops. The situation in terms of self-sufficiency of food crops is quite decimal, as the demand and supply imbalance in food crops is continuously increasing with the increasing population. This declining trend in area share of foodgrain crops is acceptable as long as productivity is increasing. Therefore, the burden of self-sufficiency cannot be completely shifted to the Jammu region as it specializes in foodgrain crops.

\section{References}

[1] P.L. Pingali, and M.W. Rosegrant, Agricultural commercialization and diversification: Processes and policies, Food Policy,Vol. 20 , 1995, 171-186.

[2] R. Chand, Diversification through High Value Crops in Western Himalayan Region: Evidence from Himachal Pradesh, Indian Journalof Agricultural Economics, Vol. 41(4), 1996, 432-441.

[3] P.K. Joshi, A. Gulati, P.S. Birthal, and L. Tewari, Agricultural Diversification in South Asia: Patterns, Determinants and Policy Implications, Economic and Political Weekly, Vol.39, 2004, 12-18.

[4] D.Jha, Rapporteur's Report on Diversification of Agriculture and Food Security in the Context of New Economic Policy, Indian Journal of Agricultural Economics Vol. 51, 1996,829-832.

S.D. Swant, and C.V.Achuthan, Agricultural Growth across Crops and Regions: Emerging Trends and Patterns, Economic and Political Weekly, Vol. 30. 1995, 17-25.

[6] V.S.Vyas,Diversification in Agriculture: Concepts, Rationale and Approaches,Indian Journal of Agricultural Economics, Vol. 51, 1996, 430-441. 